\title{
DESAFIOS E PERSPECTIVAS DA JUSTIÇA \\ NO MUNDO CONTEMPORÂNEO ${ }^{1}{ }^{2}$
}

\section{CHALLENGES AND PROSPECTS OF JUSTICE IN CONTEMPORARY WORLD}

\begin{abstract}
Aluisio Gonçalves de Castro Mendes
Professor Titular de Direito Processual Civil na Faculdade de Direito da Universidade do Estado do Rio de Janeiro; Professor Titular de Direito Processual no Programa de PósGraduação em Direito da Universidade Estácio de Sá; Desembargador Federal no Tribunal Regional Federal da $2^{\mathrm{a}}$ Região; Presidente da $3^{\text {a }}$ Seção Especializada do TRF-2; Especialista em Direito Processual Civil pela Universidade de Brasília (UnB); Mestre em Direito pela Universidade Federal do Paraná (UFPR); Mestre em Direito pela Johann Wolfgang Universität (Frankfurt am Main, Alemanha); Doutor em Direito pela Universidade Federal do Paraná (UFPR), em doutorado cooperativo com a Johann Wolfgang Universität (Frankfurt am Main, Alemanha); Pós-Doutor em Direito pela Universidade de Regensburg (Alemanha); Diretor do Instituto Brasileiro de Direito Processual (IBDP); Diretor do Instituto Ibero-americano de Direito Processual; Membro da International Association of Procedural Law; Membro da
\end{abstract}

\footnotetext{
${ }^{1}$ Recebido em 26/08/2019, sob dispensa de revisão.

${ }^{2}$ O presente texto representa versão escrita e adaptada da Aula Magna da Faculdade de Direito da Universidade do Estado do Rio de Janeiro (UERJ), sob o mesmo título, proferida no dia 19 de agosto de 2019. O evento teve mesa formada pelo Diretor da Faculdade de Direito, Ricardo Lodi Ribeiro, pelo Professor Titular de Teoria Geral de Processo, Paulo Cezar Pinheiro Carneiro, pelo Secretário Geral da Academia Brasileira de Letras Jurídicas, Sergio de Andréa Ferreira, pela Chefe do Departamento de Direito Civil, Maria Teresa Moreira Lima, pela Subchefe do Departamento de Direito Processual, Flávia Pereira Hill, pela Chefe do Departamento de Direito Penal, Patrícia Glioche, pelo Coordenador de Graduação e Subchefe do Departamento de Teorias e Fundamentos do Direito, Cleyson de Moraes Mello, e pela Diretora do Centro Acadêmico Luiz Carpenter, Fabienne Bastos Louzada.
} 
RESUMO: O presente texto é a versão escrita da Aula Magna ministrada pelo autor na Faculdade de Direito da Universidade do Estado do Rio de Janeiro (UERJ), como atividade de abertura do segundo semestre letivo de 2019. O trabalho encontra-se subdividido em cinco partes, sendo a primeira destinada à análise dos desafios da Justiça; a segunda às leituras jurídicas fundamentais; em seguida, propõe-se reflexões sobre a Justiça na realidade contemporânea; após, apresenta-se as perspectivas acerca da Justiça; e, por fim, são lançadas algumas observações derradeiras.

PALAVRAS-CHAVE: Realidade contemporânea. Justiça. Desafios. Perspectivas.

ABSTRACT: The present text is the written version of the Master Lecture given by the author at the Law School of the State University of Rio de Janeiro (UERJ), as the opening activity of the second academic semester of 2019. This article contains five parts. The first is dedicated for the analysis of the challenges of justice; the second to the fundamental legal readings; thereafter, reflexions about justice in contemporary reality are proposed; then we presented the perspectives of the justice; and finally some final remarks are launched.

KEY WORDS: Contemporary reality. Justice. Challenges. Prospects.

A Justiça é, antes de mais nada, um sonho. E há, nesse sonho, desafios que são universais. O primeiro deles está relacionado com as próprias fontes do Direito. Busca-se a formação ideal do Direito. Tradicionalmente, há duas famílias jurídicas: uma família considerada de Common Law, que possui como base o costume, e uma família de Civil Law, em que há o primário da lei. Essa separação, que talvez tenha sido mais clara no passado, já não é tão marcante nos momentos atuais. Fala-se isso porque o debate que havia acerca da jurisprudência ser ou não uma fonte do direito, hoje dá lugar ao texto expresso na lei, no Código de Processo Civil de 2015, denominado Código Fux, que foi organizado e elaborado 
por alguns professores desta casa, sob a presidência do Ministro e Professor Luiz Fux, sob o trabalho hercúleo do Professor Paulo Cezar Pinheiro Carneiro e com a colaboração importantíssima do Professor Leonardo Greco.

Então, hoje, no Código de Processo Civil, há os precedentes judiciais - não todos, mas alguns estão relacionados no artigo 927 - que têm um efeito vinculativo, e não só o efeito persuasivo, aproximando, como o professor José Carlos Barbosa Moreira já dizia $^{3}$, as duas famílias jurídicas. É claro que isso também não resolve todos os nossos problemas, porque, enquanto se tem o comando geral, seja na lei ou na tese firmada pelo precedente, e isso vem com o objetivo de proporcionar a isonomia, há sempre o caso concreto a ser analisado. O advogado, o promotor, o defensor e o juiz devem analisar com todo cuidado o caso concreto. Exatamente para não aplicar indevidamente a lei ou o precedente a casos que não possuem a mesma circunstância essencial do comando legal ou do precedente.

A Justiça sempre teve também um desafio subjetivo: quem deve resolver os conflitos? Deve prevalecer a auto composição ou a chamada adjudicação, a decisão pelo Poder Judiciário? Trata-se de uma questão talvez até religiosa, que é a difícil função de julgar o semelhante. E, por isso, todos aqueles que já vislumbram ou desejam a carreira de juiz devem pensar nas responsabilidades daí decorrentes. Como recrutar ou formar os julgadores? São sistemas diferentes, há juízes leigos no Tribunal do Júri, juízes eleitos nos Estados Unidos, concurso público no Brasil e as indicações políticas. É claro que, nesse peculiar, há que se salientar que a Justiça brasileira anda razoavelmente bem. O processo de concurso público é um processo que garante a possibilidade de qualquer um chegar a essa função a partir de uma seleção técnica e de seus próprios méritos. Todavia, o juiz não pode deixar de lado toda a sua humildade, devendo julgar o seu semelhante, analisando com muito cuidado todos os detalhes. Há uma brincadeira que fazem com os juízes no intuito de mostrar que, muitas vezes deixando-se levar pelo brilho da função, acabam se distanciando da realidade. Tal brincadeira é a de que os juízes se encontram divididos, porque a metade acha que são deuses e a outra metade tem certeza de que são deuses. O Poder Judiciário deve primar pela autoridade e pela humildade, ainda que esta composição não seja fácil de se realizar. Precisa estar numa posição de equilíbrio com os outros Poderes, porque deve

\footnotetext{
${ }^{3}$ BARBOSA MOREIRA, José Carlos. O processo civil brasileiro entre dois mundos, Revista da EMERJ, Rio de Janeiro, v. 4, n. 16, p. 11-22, 2001.
} 
respeitar a lei aprovada e o governante eleito, não obstante o judicial review que deve sempre exercer quanto à constitucionalidade das normas e o controle dos atos administrativos. Equilíbrio, urbanidade e imparcialidade também com as partes e com advogados, e o juiz deve ter todo cuidado nesse sentido. Precisa manter a equidistância, mas não pode deixar de ouvir e de considerar os argumentos lançados por todos os sujeitos processuais.

Há desafios que são e continuarão sendo difíceis. O tema da busca da verdade, enfrentado por Michele Taruffo ${ }^{4}$, para a consecução da justiça, se dá através das provas que são fontes indiretas e, por sua vez, todo magistrado e todo o julgador - porque não é apenas o juiz do Estado, pois função análoga é também exercida pelos árbitros, nas arbitragens realizam essa busca da verdade através das provas. Ocorre que, obviamente, essas provas possuem limitações, limitações, por vezes, do próprio tempo, que pode dificultar ou impedir a reconstituição dos fatos.

Busca-se também o contraditório, o debate. O juiz deve entender que esse debate enriquece a sua decisão, porque permite exatamente que se olhe todos os lados. O contraditório, por outro lado, possui limites, uma vez que esse debate não pode durar dez, vinte, trinta anos. Por isso, o dilema de que o processo tem que possuir uma duração razoável, mas não pode ser rápido demais, a ponto de não permitir que haja o contraditório, que não haja a busca da verdade na colheita das provas.

Deve-se, do mesmo modo, atenção especial à fundamentação. A decisão judicial deve vir sob fundamentos fortes no intuito de convencer ambas as partes, embora seja um desiderato um pouco difícil, porque ao decidir a favor de uma das partes, o juiz está deixando insatisfeita a outra parte. Na motivação reside boa parte da legitimidade do Poder Judiciário, que não é eleito no Brasil e na maioria dos países. Portanto, a legitimidade do Judiciário vem da sua escolha e da fundamentação. Sabe-se da dificuldade decorrente do volume de muitos processos a serem apreciados e movimentados, mas obviamente o juiz deve buscar o equilíbrio. O juiz não deve formular, sem que precise, uma sentença de cem ou duzentas páginas, porque provavelmente estará deixando de lado vários outros processos. Então, ele deve sempre dar a fundamentação necessária, abarcando as alegações das partes, as manifestações dos sujeitos processuais, as questões jurídicas e fáticas, as provas produzidas, os incidentes e questões processuais e as razões que o levaram às conclusões.

\footnotetext{
${ }^{4}$ TARUFFO, Michele. Uma simples verdade: o juiz e a construção dos fatos. Trad. Vitor de Paula Ramos. São Paulo: Marcial Pons, 2012.
} 
O sistema, com o novo Código de Processo Civil, também buscou o equilíbrio em relação à impugnação das decisões. Aliás, essa difícil arte de julgar é pensada, sob o ponto de vista dos tribunais, no sentido de se delegar ao colegiado, porque um conjunto decide melhor, consegue analisar melhor do que uma única pessoa. Mas, até que ponto se pode permitir incessantes recursos? Então, com o novo Código de Processo Civil, houve um debate intenso em torno das possibilidades de impugnações de modo mais amplo, ou não, das decisões judiciais. O desiderato de justiça leva à defesa de um sistema mais aberto e condescendente com as impugnações. Contudo, a duração longo dos processos pode ser o resultado cada vez mais incompatível com o dinamismo dos dias atuais.

A efetividade do processo. O processo, no passado, era dotado de um formalismo muito grande, mas hoje em dia busca-se a sua efetividade, dando maior importância ao cumprimento e realização dos julgados, buscando o que se fala processo de resultados.

\section{LEITURAS FUNDAMENTAIS}

Há uma obra de Francesco Carnelutti que se chama "Como se faz o processo". Carnelutti foi um grande jurista italiano, que nasceu no final do Século XIX e faleceu em 1965. Ele foi professor nas Universidades de Pavia, Milão e Roma. O primeiro capítulo do seu livro recebe o apropriado título de "O drama". Depois de mencionar as agruras do Processo Penal e do Processo Civil, surge o capítulo destinado ao juiz. Nas palavras de Carnelutti, é alguém que, em primeiro lugar, tem juízo, ou pelo menos deveria ter, poder-seia complementar. Contudo, "quem possui ou possuirá", pergunta Carnelutti, "a ciência do juízo?"

Piero Calamandrei foi outro italiano de renome no cenário mundial. Dez anos mais novo que Carnelutti, além de advogado, foi professor nas Universidades de Messina, Modena, Siena e Florença e escreveu o indispensável livro que recebeu na Itália o título "Elogio dei Giudici", aqui no Brasil traduzido para "Eles, os juízes, vistos por um advogado" ${ }^{6}$. Discute-se se o título foi uma ironia ou, de fato, um elogio verdadeiro. Todavia, parece que há as duas coisas no livro, porque Calamandrei enaltece determinadas condutas

;5 CARNELUTTI, Francesco. Como se faz um processo. Traduzido por Hebe Caletti Marenco. São Paulo: Minelli, 2002.

${ }^{6}$ CALAMANDREI, Piero. Eles, os juízes, vistos por um advogado. Trad. Eduardo Brandão. 2. ed. São Paulo: Editora WMF Martins Fontes, 2015. 
judiciárias que devem ser valorizadas. Entretanto, ironiza, com razão, certas patologias, atividades práticas que não se coadunam com as atividades do juiz, que acabam ocorrendo no dia-a-dia. Ele retrata, no livro, as virtudes e vicissitudes do exercício da judicatura, que se projetam, também, em outras profissões jurídicas e que podem, para o bem ou para o mal, interferir na busca da Justiça.

O terceiro livro que também deve ser recomendado, para os iniciantes e iniciados que leram, é o "Acesso à Justiça"7, de Mauro Cappelletti em conjunto com o norte-americano Bryant Garth, que foi fruto de uma pesquisa muito importante feita no cenário internacional. O primeiro problema, que tem muito a ver com a história do Direito, diz respeito ao aspecto econômico que é o da justiça cara e distante. Para se fazer frente a isso, Cappelletti e Garth verificaram o problema e que, para resolvê-lo, ou atenuá-lo, foram criados os meios de assistência judiciária, não só de disponibilização de advogados, mas também do fornecimento de informações e outras possibilidades de acesso à Justiça. No Rio de Janeiro, a Defensoria Pública e os Escritórios Modelos nas Faculdades de Direito são um exemplo vivo deste trabalho importantíssimo de ampliação do acesso à Justiça. Fiz questão de estagiar no Escritório Modelo da Faculdade de Direito da UERJ e vários foram os casos práticos de atuação, um verdadeiro aprendizado para a vida. Pessoas que batem aqui - muitas vezes, pessoas pobres; por vezes, emocionalmente abaladas - e os professores, estagiários e colaboradores têm a função de levantar a vida e a defesa dos direitos dessas pessoas.

\section{SOBRE A JUSTIÇA NA REALIDADE CONTEMPORÂNEA}

Em primeiro lugar, outro título digno de ser invocado e lido é “A Era dos Direitos" ${ }^{\prime \prime}$, de Norberto Bobbio. Temos de luzes, tempos em que o Estado Democrático de Direito se consolida e passa a existir na maioria dos países e, com isso, nunca se teve no mundo um acesso tão amplo ao Judiciário, a ponto desse acesso virar um problema, como se demonstrará, em seguida, com números e estatísticas.

Em segundo lugar, o filósofo polonês Zygmunt Bauman traz uma expressão da atualidade, que é a chamada "modernidade líquida". Significa que não se tem mais a

\footnotetext{
${ }^{7}$ CAPPELLETTI, Mauro; GARTH, Bryan. Acesso à justiça. Trad. Ellen Grancie Northfleet. Porto Alegre: Fabris, 1988.

${ }^{8}$ BOBBIO, Norberto. A era dos direitos. Trad. Carlos Nelson Coutinho. Rio de Janeiro: Elsevier, 2004.
} 
durabilidade, a perpetuidade, aquela existência atemporal de valores imodificáveis; a realidade contemporânea se altera a todo momento e se precisa saber conviver com essas circunstâncias inovadoras. E isso faz com que haja uma certa insegurança, porque o Poder Legislativo não tem a velocidade suficiente para prever o que vai acontecer hoje ou amanhã. O resultado disso são relações jurídicas, fatos, que ainda não estão regrados, sob ponto de vista legislativo. E quando há conflitos, a quem se procura? Exatamente ao Poder Judiciário, que passa a ter um papel de destaque, não só nos conflitos privados, mas também no aspecto político de equilíbrio entre os Poderes e, por isso, o Poder Judiciário, que é tido como um Poder lento, passa a ter que ser um Poder mais rápido. Em vários países, como no Brasil, há uma proibição de não se julgar, ou seja, a inafastabilidade da prestação jurisdicional traz o dever de qualquer conflito ou ameaça de lesão ter de ser decidido pelo juiz. Ainda que não haja lei, uma norma ou regra específica, se levarem o conflito ao Poder Judiciário, em dias normais ou mesmo em plantão judiciário, o juiz terá que decidir, talvez pela primeira vez, aquele conflito, se houver uma situação de urgência. Então, o Poder Judiciário consegue ser o mais lento e, ao mesmo tempo, o mais rápido, quando se depara com um requerimento de liminar ou tutela provisória, como ocorre com frequência nos dias atuais.

Obviamente, não se pode tornar o Poder Judiciário algo maior do que tudo. Não se pode transferir para o Poder Judiciário a resolução de todos os conflitos. Isso é impossível e por isso é que se deve ter responsabilidade. É muito feliz essa expressão inglesa, que é a de compliance, que nada mais é um cumprimento de normas, de princípios e de regras. Com efeito, não se pode olhar apenas para os direitos, se não se cumprir também os deveres.

E, sob outro aspecto, outra questão fundamental relacionada são as soluções consensuais. O direito, até pouco tempo atrás, era vocacionado para o conflito, para a guerra. Hoje, as faculdades de direito possuem o papel de criar outra cultura, de fornecer profissionais abalizados para a solução, extrajudicial ou mesmo judicial, de modo consensual e, para isso, precisa-se de pessoas que estejam devidamente conscientes e preparadas tecnicamente para realizar negociações, conciliações e mediações. Para tanto, é preciso se formar, estudar, experimentar e praticar, para se realizar, a contento, essa atividade diplomática, e com isso reduzir essa quantidade de processos que existem no judiciário.

Só para se ter uma ideia: em 1950, o Supremo Tribunal Federal recebia 3.000 processos por ano; em 2002, dos 3.000 chegou a 160.000 por ano. Uma Corte com 11 juízes recebendo 160.000 processos por ano, significa praticamente 16.000 por mês; mais de mil 
processos para cada ministro. Cada ministro tendo 15 minutos para analisar e fazer tudo em um processo, não é razoável. Isso traz demora nos julgamentos, sensação de impunidade e injustiça.

Outro problema é que essa quantidade imensa traz também tratamento desigual diante de questões idênticas e, portanto, insegurança jurídica. Por isso, a importância da instrumentalidade processual. Na técnica, não a serviço do formalismo, mas a serviço da efetividade, da eficiência do processo. Um processo tem que ser bem julgado, em tempo razoável. Para isso, obviamente, as estruturas e a cultura precisam mudar. Deve-se aprimorar um trabalho de gerenciamento nos tribunais, de gestão de pessoal e de processos.

\section{PERSPECTIVAS DA JUSTIÇA}

O primeiro eixo das mudanças recentes do Direito Processual é voltado para o fortalecimento da jurisprudência e do precedente. Houve aqui uma nova concepção, elaborada por essa nobre comissão de juristas, que foi de fortalecer o caminho, que já tinha sido iniciado, de dar maior importância para a jurisprudência. Não poderia continuar acontecendo de os Tribunais Superiores firmarem uma tese, mas cada juiz continuar julgando da forma que entendesse melhor, diante de questões idênticas. Por isso, criou-se um sistema de precedentes com efeito vinculativo. O resultado que se quer disso é a diminuição da quantidade dos processos, a partir de uma segurança jurídica maior, e haverá uma garantia de isonomia, pois todos estarão sendo julgados sob a mesma tese e sob o mesmo direito.

Essa uniformização não pode ser vista de um modo insensível para os casos concretos. É importante que se analise cada caso concreto e se vejam as peculiaridades que eles podem ter. Também os precedentes possuem uma técnica de construção que, a partir de agora, será muito importante na Faculdades de Direito, tanto do ponto de vista da construção do precedente, quanto das hipóteses de superação ou até de distinção em relação ao precedente. O sistema de precedente é bom, mas tem que expressar as normas e a consciência da sociedade; ele tem que estar aberto para as mudanças que a sociedade também proporciona. Se assim não fosse, ainda teríamos muitas injustiças em vários países de Common Law. A aplicação de precedentes é, portanto, fundamental e exige o devido estudo. 
Junto com os precedentes, veio o sistema de gestão de demandas, principalmente para as chamadas demandas repetitivas. Os professores costumam falar de Caio e de Tício, lecionando o Direito Romano, mas hoje em dia as relações jurídicas não são exatamente entre Caio e Tício, mas, sim, entre bancos, companhias que vendem produtos ou serviços em escala, servidores públicos, tributos, isto é, relações de massa e, por isso, há essa quantidade de demandas repetitivas que chegam ao Judiciário. Nesse contexto, foi elaborado esse sistema de gestão calcado basicamente em dois instrumentos que são os recursos repetitivos e o incidente de resolução de demandas repetitivas (IRDR).

Essa técnica também envolve uma harmonização melhor da Justiça, porque ao invés de ter 16 ou 17 mil juízes no Brasil inteiro debruçando-se e decidindo a mesma coisa, delega-se para alguns tribunais poderem decidir e já uniformizar a questão, trazendo racionalidade e eficiência para o Poder Judiciário. Então, é uma nova forma de pensar para os tempos modernos, em que há uma necessidade de rapidez, porque o Poder Judiciário não pode, em tempos de internet de velocidade de vários gigabytes, continuar julgando em décadas, mas precisa julgar em tempo razoável e condizente com a realidade contemporânea.

Também não se pode continuar entendendo a Justiça como Poder Judiciário e, portanto, muito atual o que Cappelletti falou, e que foi anteriormente mencionado, que são os meios consensuais, meios alternativos ou meios adequados para resolução de conflitos. E, nesse aspecto, há, no Brasil, por exemplo, os Juizados, que antes foram denominados de Juizados de Pequenas Causas e que, agora, receberam uma denominação mais apropriada: Juizados Especiais. Há, também, a arbitragem para os conflitos específicos que exigem uma certa especialização. E, ainda, no próprio Poder Judiciário, a especialização dos tribunais, porque, apesar de se dizer que o juiz deve conhecer o Direito, não se pode ter a ilusão de que ele sabe todas as matérias, então, a especialização é muito importante. E há, também, meios modernos que compatibilizam a solução consensual com a tecnologia, como o chamado Online Dispute Resolution (ODR) ou meios de resolução de conflitos através das plataformas eletrônicas, que ajudam muito, seja para resolver os conflitos no âmbito da própria empresa, diretamente com os seus consumidores, ou também no âmbito da Administração Pública.

Mauro Cappelletti, portanto, pensou na assistência judiciária, pensou nos meios adequados e pensou nas soluções coletivas, dentre as quais a Ação Civil Pública no Brasil ou as class actions, no direito norte-americano. E, no âmbito dos meios consensuais, precisa- 
se evoluir muito, especialmente no Brasil. Só para se ter uma ideia, segume alguns números. Em termos de soluções consensuais no país, a Justiça do Trabalho é a campeã, pois resolve em torno de $25 \%$ dos casos amigavelmente; a Justiça Estadual resolve $11 \%$ dos casos de forma consensual; e a Justiça Federal, em 2016, apenas 4\%, quase dobrando, contudo, em 2017, para 7\%. Em comparação com a realidade de outros países, na média, o Brasil tem 7\% no âmbito de Justiça Federal, já os Estados Unidos têm 91\% dos casos resolvidos consensualmente e o Canadá possui $83 \%$. São dados que indicam uma diferença gritante entre as realidades nacionais.

Essas mudanças mencionadas precisam de transformações culturais e estruturais. Quanto ao aspecto estrutural, pode-se apontar que os Tribunais precisam se organizar de forma mais eficiente, o sistema jurídico precisa trabalhar melhor, do Supremo à Primeira Instância. O Supremo Tribunal Federal chegou a esses números, porque, na Constituição de 1988, o legislador não estabeleceu nenhum filtro e isso veio a ser modificado depois, somente em 2004, mas, ainda assim, um filtro que foi sendo utilizado com muita parcimônia. O resultado é um passivo difícil de ser vencido. O Superior Tribunal de Justiça não tem hoje nenhum filtro e isso faz com que cheguem 300 mil processos por ano no STJ: um número impossível de ser julgado com a devida atenção e rapidez. Precisa haver mais especialização em todos os Tribunais e os profissionais do Direito, a começar pelos magistrados, também a entender o papel e a importância da uniformização.

Calamandrei, no livro anteriormente apontado, mencionava que, em determinado caso, envolvendo um cavalo, em que se discutia a responsabilidade civil de uma alegada mordida ou não, uma pessoa, havia prova tranquila nos autos de que o cavalo não havia mordido. No entanto, o juiz levou para o caso uma experiência pessoal: o sobrinho dele havia sido mordido por um cavalo e daí ele tirou a conclusão de que o cavalo do caso teria mordido a vítima. O juiz precisa estar consciente, antes de mais nada, que ele é um aplicador do Direito. Então, precisa se basear no sistema jurídico e não apenas nas suas convicções pessoais. E isso também é muito importante no sistema de precedentes, porque ele tem que atuar a favor dessa uniformização, então ele tem que contribuir para a uniformização e depois seguir o que os Tribunais estão julgando. Do contrário a mudança não ocorrerá ou demorará um tempo muito grande para se efetivar. A mudança que se aguarda deve ocorrer não apenas com os juízes, porque se os estudantes de Direito não começarem a estudar também os precedentes, eles também não estarão preparados depois 
para a advocacia, porque a advocacia não é mais apenas estudar as leis, mas também estudar as decisões dos Tribunais para discutir os argumentos dessas decisões e, eventualmente, levar ao seu cliente essas decisões, ao invés de ajuizar apenas uma ação sem a menor chance de sucesso.

Em relação ao tempo do processo, como mencionado, o tempo para a sociedade hoje é outro. Por isso, o fortalecimento das chamadas tutelas sumárias, das tutelas provisórias, que não podem aguardar muito tempo até a solução final do processo. Do mesmo modo, também há a necessidade de controle da produtividade interna do Poder Judiciário em relação aos servidores e aos magistrados. Foi-se o tempo em que o juiz achava que poderia decidir quando ele quisesse. Há que se ter um controle não só da conduta do juiz, um balizamento de atuação, de correção e de produtividade perante a sociedade, é preciso, antes de mais nada, exercer bem e com duração razoável no julgamento dos processos.

Caminhando para o final, há que registrar o aspecto da universalização. Hoje não há um Direito puramente nacional. Na Faculdade de Direito, em todos os ramos do Direito, e até fora dele, o conhecimento é trocado entre profissionais e academias do mundo inteiro e, por isso, é muito importante o estudo do Direito Comparado. De certo modo, em alguns países, há uma tendência de uniformização e harmonização entre as normas aplicáveis. Vejam a União Europeia e, de certo modo, em menor escala, o Mercosul. Há também Cortes judiciais e arbitrais internacionais. E mais, fala-se de precedentes internacionais, porque há questões universais, como, por exemplo, as de gênero e discriminação, que existem atualmente no mundo inteiro e que muitas vezes o julgado de um país servirá de referencial para outro. A academia pode melhorar quando estuda os países vizinhos ou outros países, para cotejar, trocar experiências e evoluir no próprio Direito.

Uma outra coisa quase inadmissível no país é a falta de integração dentro do próprio Poder Judiciário. Pode-se dizer isso com um certo conhecimento de causa, que não há ainda uma integração suficiente entre os Tribunais a nível nacional. Só para ter uma ideia, muitas vezes a pessoa comete um crime bárbaro em um estado, foge e não é presa em outro, porque não há essa integração para o efetivo cumprimento do mandado de prisão em outro estado. Há que evoluir nesse sentido e na utilização mais ampla das possibilidades decorrentes do avanço dos meios tecnológicos, em termos de comunicação, transparências, inteligência artificial etc. 
Em primeiro lugar, a importância do Direito no caso concreto. Quem leciona na Graduação e na Pós-Graduação, ou tem uma atuação profissional na advocacia, na magistratura ou no Ministério Público, por vezes, acaba não examinando a fundo o caso concreto. Há estudantes que fizeram bem o seu papel e estudaram muito durante os cinco anos. Entretanto, quando vão preparar alguma peça jurídica, falam de todas as normas e de todos os precedentes, mas esquecem dos elementos do caso específico. Isso não pode acontecer. O profissional do Direito tem que analisar cada caso, porque sempre pode haver uma peculiaridade que faz com que aquele caso não se enquadre no precedente que se pensava. Isso é muito importante, porque cada processo, como já se disse antes, traz a vida, a liberdade, o patrimônio da pessoa e, portanto, aquela decisão pode influenciar decisivamente na vida e na trajetória de uma ou de várias pessoas. Portanto, deve-se reforçar a necessidade dessa ligação da Justiça com o ensino. Esses desafios precisam ser desenvolvidos principalmente no âmbito da academia. E, por isso, reitera-se a necessidade de aprimoramento do estudo, do aprendizado e da evolução das técnicas de negociação, mediação e conciliação para que se tenha profissionais preparados, porque não é só a boa vontade de querer conciliar, há que se aprender a fazer isso com resultados positivos.

Em segundo lugar, cabe acentuar, também, a questão da ética e da fidúcia na relação entre os profissionais do Direito. Quando era aluno da Universidade do Estado do Rio de Janeiro, fora convidado para ser estagiário dos professores Evaristo de Moraes e George Tavares. Em certa ocasião, logo no início, houve a oportunidade de acompanhá-los em uma audiência com um magistrado. Evaristo começou a falar, contando em detalhes o caso e, de certa forma, com alguns aspectos negativos para o cliente, no intuito de o juiz ficar ciente de toda a realidade. Além disso, levou um volume grande de documentos para o julgador verificar os fatos narrados. Quando o Evaristo acabou de falar, o magistrado se virou para a máquina de escrever e começou a datilografar a sua decisão. Ele não precisou ler a petição, nem conferir os documentos. Isso se chama fidúcia, porque era a reputação que ele tinha perante o Poder Judiciário e perante aquele juiz, que não tinha intimidade com ele, mas sabia da sua conduta. Isso basta para ter credibilidade e isso é muito mais importante do que dezenas de páginas escritas. 
Por fim, falaria que cada magistrado, cada promotor, cada advogado, cada professor e cada estudante de direito tem o seu papel na melhoria do Direito. Não menosprezem essa capacidade. Foi marcante, como estudante dessa Faculdade, no Escritório Modelo, a experiência vivida, quando se teve a oportunidade de se conseguir a liberdade de um rapaz que tinha sido preso injustamente. E depois, como magistrado, embora não seja perfeito, sempre fiz e procurei fazer o melhor para colocar o meu órgão jurisdicional em dia, julgando com equilíbrio em termos de qualidade e de duração razoável. Então, cada um de vocês tem um papel nessa história, deve ser ressaltado que cada um de nós e cada estudante poderá colocar o seu tijolo nessa construção que se chama Justiça.

\section{REFERÊECIAS:}

BARBOSA MOREIRA, José Carlos. O processo civil brasileiro entre dois mundos, Revista da EMERJ, Rio de Janeiro, v. 4, n. 16, p. 11-22, 2001.

BOBBIO, Norberto. A era dos direitos. Trad. Carlos Nelson Coutinho. Rio de Janeiro: Elsevier, 2004.

CALAMANDREI, Piero. Eles, os juízes, vistos por um advogado. Trad. Eduardo Brandão. 2. ed. São Paulo: Editora WMF Martins Fontes, 2015.

CAPPELLETTI, Mauro; GARTH, Bryan. Acesso à justiça. Trad. Ellen Gracie Northfleet. Porto Alegre: Fabris, 1988.

CARNELUTTI, Francesco. Como se faz um processo. Traduzido por Hebe Caletti Marenco. São Paulo: Minelli, 2002.

TARUFFO, Michele. Uma simples verdade: o juiz e a construção dos fatos. Trad. Vitor de Paula Ramos. São Paulo: Marcial Pons, 2012. 